that the final radius when the star has returned to approximately its initial total brightness may be perhaps $1 / 25$ of the pre-outburst radius. The net consequence of the outburst being thus a contraction of the whole star, it results in the liberation of a vast amount of gravitational energy of which some, at any rate, must supply the energy for the increased radiation during the eruption.

The variation of brightness of a nova is accompanied by a highly complex sequence of changes in its spectrum. Before the principal maximum the spectrum is not greatly different from one of the ordinary spectral types. The absorption lines, which are then its chief feature, show by their displacement towards the violet the general swelling up of the star already deduced from its increase in brightness. After maximum, multiple absorptions appear with large violet displacements, and each in general bordered on the redward side by bands of emission the mean position of which coincides in each case with the undisplaced position of the corresponding spectral line. These features can be explained by supposing that one or more shells of gas are thrown off from the star and accelerated away from it, probably under forces due to radiation pressure. This has in some cases been confirmed by the fact that, after enough time has elapsed for these shells to attain sufficient size, it has been possible to observe them directly as a growing nebulosity around the parent star. There is also spectroscopic evidence in some cases for the ejection of matter in irregular jets rather than, or as well as, in symmetrical shells. In addition, turbulence appears to develop in the ejected matter.

In the further spectral development the absorptions gradually disappear, giving way to a bright line spectrum in which a number of 'forbidden' lines of oxygen $[\mathrm{O} \mathrm{I}]$ and $[\mathrm{O} \mathrm{III]}$, and iron [Fe II], make their appearance. The whole sequence is consistent with what may be expected from the increase of temperature of the parent star and the decrease in density of the expanding envelope. The final spectrum is of Wolf-Rayet type, the structure of the lines suggesting the continued emission of gas. It seems probable that the nova is then approaching a white dwarf state.

Photometric measurements of novæ spectra have recently yielded valuable information confirming both the hypothesis of the expanding gaseous shells and also the high colour temperature attained by the nuclear star in the later stages. Further, the photometry of the absorption lines due to interstellar $\mathrm{Ca}^{+}$yields an estimate of the distance of the nova. This method gave for Nova Herculis a distance of 1,200 light-years, which shows that at maximum it was 30,000 times as bright as the sun.

The estimated rate of appearance of novæ in the Milky Way agrees well with Hubble's estimates of the number appearing in the Andromeda nebula, which may be regarded as a comparable system. If this rate is assumed uniform, it shows that in about $3 \times 10^{9}$ years every star would become a nova. This is approximately equal to the lowest estimate of the age of the stars, so it seems likely that such a flare up may in fact happen to every star. The most plausible explanation of the phenomenon is provided by E. A. Milne's theory, according to which instability sets in at a certain epoch in the evolution of a star, causing it to pass over into a 'collapsed' configuration, with the liberation of a large amount of gravitational energy. The same theory shows that, if the star is originally rotating, the collapse may cause it to split into two components, which need not then remain collapsed, thus suggesting an origin for double stars.

It is extremely doubtful whether novæ constitute a homogeneous class of objects. Whereas the total brightness in most cases increases tenor a hundred-thousand fold, it seems that the nova of 1572 underwent an increase of about 16 million fold. Similar cases have been observed in other galaxies. So the isolation of a class of super-novæ is indicated, and it has been suggested by Baade and Zwicky that their outbursts provide the source of cosmic radiation. Again the behaviour of stars like RS Ophiuchi and T Pyxidis makes it seem probable that there is also a class of recurrent novæ.

W. H. MoC.

\title{
Geological Relations of Early Man in East Anglia
}

$\mathrm{T}$ HE discussion on this topic, held on September 5 at the Norwich meeting of the British Association, has revealed a far greater measure of agreement between geologists and archæologists than has emerged during any previous review of the subject. The division of the East Anglian glacial deposits into four distinct groups has pro- vided a framework into which most of the archæological finds appear to fit quite naturally ; it is thus not surprising that discussion should now centre around the more obvious of the remaining doubts and difficulties.

The first of these concerns the authenticity and cultural position of the various sub-Crag industries. 
The best pieces from this horizon are now fairly generally accepted as human, both by geologists and archæologists; but some enthusiasts among the latter are apt to spoil their case by the obstinate adrocacy of a great deal of poorer material which, convincingly human as it may be to their experienced eyes, can scarcely be expected to impress geologists who lack their special knowledge of these early industries. In any event, it is becoming increasingly clear that no general agreement can ever be obtained as to the exact position of the beginning of the Stone Age ; but it seems justifiable to record a majority of informed opinion in favour of the human origin of some at least of the flints found below the East Anglian Crags. Some archæologists claim to recognise a Chellian facies in these cultures; but there are not many who would support their reference to the Chellian as usually recognised at present.

The next difficulty is the determination of the geological position of the true Chellian culture. This is largely due to the occurrence of a depositional hiatus between the first ('North Sea') and second ('Great Eastern') glaciations. Further, with the exception of one implement found by Mr. J. E. Sainty in the North Sea Drift, all the known Chellian specimens from East Anglia are heavily abraded, and are clearly much older than the deposits in which they are now found. Mr. Sainty's implement appears to indicate a preglacial date for the industry, and this accords well with its occurrence at Abbeville in association with a Cromerian fauna ; but in that case it was probably of very long duration, since the Acheulian industry does not appear in England until after the second glaciation. It is to be hoped that further study of the deposits belonging to the first interglacial period, such as occur in the Midlands, will provide some help towards the solution of this problem.

The Acheulian of East Anglia appears to belong entirely to the second interglacial period. The only possible exceptions are provided by a few pieces found by Mr. J. Reid Moir in the so-called 'Upper Chalky Boulder Clay' and associated gravels in the Ipswich district. But as this 'Upper' boulder clay is no more than a surface modification of the great sheet of Chalky Boulder Clay which covers most of Norfolk, Suffolk and Essex and is known to underlie the Acheulian brickearths at Hoxne and at Derby Road, Ipswich, it seems reasonable to regard Mr. Moir's specimens as having reached their position from the surface; this could be explained either by later solifluxion or by descent into frost cracks.

It is now generally accepted that the flake industries of Clacton and High Lodge were broadly contemporaneous with the Acheulian, although the exact parallelism of their various stages has not yet been fully worked out.

The deposits of the third ('Little Eastern') glaciation frequently contain Acheulian and Clactonian implements. They have long been known from Gresham on the Cromer Ridge and from the gravels of the Breckland; Mr. Sainty has recently been finding them at several new localities in West Norfolk.

The archæological history of the third interglacial period is a matter of doubt. Apart from a few scattered Upper Palæolithic finds, the prevalent culture belonging to this interval is a curiously mixed assemblage suggestive of a degenerate Levalloisian or even Clactonian industry with traces of Upper Palæolithic influence. As it occurs largely on surface sites of no stratigraphical value it has been somewhat summarily referred to the Neolithic by many archæologists, in spite of the fact that real Neolithic forms and technique are wanting. Mr. Reid Moir's 'Lower Floor' at Bolton's pit, Ipswich, represents this industry; it is also known from Morston in Norfolk and is probably found on many surface sites in the Breckland.

It is to be hoped that archæologists will make a detailed study of this industry, which has certain well-marked peculiarities of technique and is probably peculiar to Great Britain.

The mesolithic industries are never found in glacial deposits even where the fourth glacial period is represented, and they are therefore considered as entirely post-glacial.

Such is the state of our knowledge of these problems as revealed by the recent discussion. Other points raised were the questions of nomenclature, of the position of the Pliocene-Pleistocene boundary and of the possibility of making a detailed chronological Drift map for the assistance of the archæologists.

Prof. P. G. H. Boswell suggests that the suffix '-ian' should be uniformly adopted for all the Palæolithic industries; this would appear to be logical and to follow the standard practice of British geology. The question of the PlioPleistocene boundary would eventually have to be settled by international agreement, but meanwhile there would seem to be a strong case for following the palæontologists, who place it at the horizon of the appearance of Equus, Bos and Elephas; that is to say, below the Red Crag of East Anglia.

The possibility of a detailed Drift map would seem to be small until the Pleistocene sequence has been correlated over the whole country; archæologists will therefore have to rest content with the ever-increasing number of criteria provided by the geologists for the differentiation of the various Drift deposits.
J. D. Solomon. 